\title{
Triggers of Emotional Highs in Experiential Learning
}

\author{
Dr Sandris Zeivots
}

International Research Centre for Youth Futures, School of Education, University of Technology

Sydney, Sydney, Australia

\section{Contact details:}

Dr Sandris Zeivots

International Research Centre for Youth Futures

University of Technology Sydney

15 Broadway, Ultimo

NSW 2007, Australia

Phone: +6129514 5594

Email: Sandris.Zeivots@uts.edu.au,Sandris.Zeivots@gmail.com

Twitter:@SandrisUTS

ORCID: 0000-0001-5450-2530

\section{Acknowledgements}

This paper is based on a larger research project that focuses on lived experience of emotional highs in experiential learning (Zeivots, 2015). 


\section{Triggers of Emotional Highs in Experiential Learning}

This study is concerned with emotional highs in experiential learning and, more specifically, determining triggers that lead to emotional highs. The research aims not only to understand the invisible side of emotions, but also genuinely consider how learners make sense of their experiences. To study the triggers of emotional highs, a deliberate decision was made to approach the phenomenon as an experience. Hermeneutic phenomenology is used as an overarching methodology. The study focused on experiences of 15 adult learners who participated in one of three experiential learning courses. The three courses were residential, lasted four to eight days and took place with an equal number of days indoors and outdoors. Learners were asked to make sense of their lived experience through surveys, reflection and semi-structured interviews. Eight themes of emotional high triggers emerged, including Sense of being pushed, Out-of-me experience and Escaping one's environment.

Keywords: experiential learning; emotional highs; positive emotions; hermeneutic phenomenology; adults.

\section{Introduction}

Something happens in experiential learning courses that many learners find meaningful and valuable, at least for a while. For an unspecific period, they feel positively changed, excited, reinvigorated. These moments appear to be highly regarded by learners. 
Scholars use different terms and metaphors to describe the state of being that learners may experience during or after experiential learning activities. Schoel, Prouty \& Radcliffe (1988) label it as 'peak experience'; Heron (1996) refers to it as an 'imaginal awakening'; Harris (1996) talks of 'energy'; Hayllar (2000) uses a chain of words that include 'fantastic', 'valued', 'worthwhile' and 'reinvented'; and Shareski (2017) calls it 'joy in learning'.

Along similar lines, Briscoe (2012) opts for a concept of 'inherent joy' and discusses it through a more critical approach. She defines the phenomenon as an inner deep satisfaction in learning, and admits that the definition is proposed with radical uncertainty. With this Briscoe attempts to initiate a discussion on understanding positive emotional experiences, specifically in the context of learning; it is an invitation to others to further refine the phenomenon.

Although differently worded, these expressions point to the similarity of the impressions emerging in experiential learning settings. Zeivots (2016) refers to these experiences as 'emotional highs' and focuses on pinning down the phenomena, understanding their essence and clarifying the ambiguity of their nature. Influenced by Briscoe's (2012) definition, Zeivots (2016) refines it further and defines emotional high as 'inner deep satisfaction a learner experiences when they have absorbed something meaningful' (p. 367). This definition contextualises the ways emotional highs are understood in this study.

While the experiential learning literature focuses primarily on understanding emotional highs, per se, this study aims to complement it by understanding the triggers of emotional highs. Understanding the triggers may not only assist educators and scholars to have a more holistic appreciation of emotional highs, but also show the importance of the interrelationship between current and past experiences and how this impinges on learning. 
Learning always relates, in one way or another, to what has gone before. There is never a clean state on which we begin; unless new ideas and new experience link to previous experience, they exist as abstractions, isolated and without meaning. The effects of experience influence all learning. (Boud, Cohen, \& Walker, 1993, p. 8)

\section{Background}

Learners constantly experience a range of feelings and emotions, sometimes concurrently (Takahashi and Saito, 2013). An increasing number of studies show the benefits of recognising the emotional dimensions, particularly positive emotions, of learning. These include increased learner interest (Ainley, Corrigan, \& Richardson, 2005; Krapp, 2005); engagement and selfregulated learning (Gläser-Zikuda, Fuß, Laukenmann, Metz, \& Randler, 2005); building of social skills (Waugh and Fredrickson, 2006); interpersonal satisfaction (Vacharkulksemsuk and Fredrickson, 2013); increased decision-making and creativity (Picard et al., 2004); and enhanced academic performance (Rodríguez-Ardura and Meseguer-Artola, 2017).

The importance of emotional learning experiences has been emphasised by Fredrickson (2004). In addition to being meaningful for optimal human functioning, positive emotional experiences can broaden a learner's thinking and attention, enhance their psychological resilience, and provide the seed for personal development. Acknowledging emotions in learning can develop more personalised and meaningful experiences that expand beyond the learning environment. In making these conclusions, Fredrickson illuminates the benefits for the learner in the learning environment as well as the individual in everyday life. 
Emotions can also be uncomfortable in the learning process. Dirkx (2008) observes that learners can experience disturbing emotions that arise from the learning environment or from within themselves. They may struggle with personal issues connected with family, relationships, work and their role in society. Emotions may erupt in surprising ways within learning groups and should therefore be seen as a double-edged sword that has the ability to enhance as well as impede learning (Wolfe, 2006).

This study of emotions in learning is largely influenced by sociocultural and sociomaterial theories (e.g. Fenwick, Edwards, \& Sawchuk, 2011) and, in particular, the work of Hochschild (1983/2003). Emotions are therefore theorised as sociocultural and sociomaterial means for understanding one's relationship to the world. They are seen not just as a part of an inherent response syndrome, but also as qualities unique to each person. In the framework of this research, emotions are experiences perceived by an individual, not events that conform to any pre-existing category.

Beard \& Wilson (2013) point out that particularly in experiential learning courses, emotional moments are encouraged and actively used as a part of learning. Assisting learners to be conscious of their emotional experiences, including pleasant and disturbing ones, allows them to manage and intensify their learning. The basis of learning, according to Harris (1996), is essentially about humans being aware of themselves as individuals: how they see, feel, think and perceive. This often directly affects emotional experiences. Emotions and feelings, Boud and Miller (1996) believe, are key pointers to both possibilities for, and barriers to, learning. Denial of emotions and feelings, they conclude, is denial of learning.

Importantly, learners not only experience a wide range of emotions, but also stimulants or triggers that affect their emotional experiences. Emotions can be triggered by different internal 
and external sources and therefore lead to different outcomes. Some triggers are constructed, some emergent, some come across as conscious, while others remain unconscious (Järvenoja and Järvelä, 2005).

For a learner to perceive all triggers with the same level of intensity would be overpowering. To avoid this, awareness and sensitivity to these triggers are crucial. Facilitators should take into account how noticeable and important the triggers are, the degree of the learner's interest in them and what other triggers are competing for attention (Beard and Wilson, 2013).

Some scholars approach triggers as merely detached elements of emotions (e.g. Plutchik, 1980); triggers are often seen as less important and appear to have limited application. This study finds this perspective problematic. At the metaphysical level, this study looks at emotions and their triggers as 'experiences' that emerge from the state of unawareness and reach the so-called emotion that one becomes aware of. In this way, the existence of objective emotional experience is rejected (Dewey, 1938/1975) and emotions are seen rather as individual experiences that may or may not be visible to external others. No two people can experience learning in the exactly same way because every interaction is personal and unique (Beard and Wilson, 2013). Similarly, approaching emotions as experiences does not require predetermined speculations around emotions as feelings, emotions or affect, as all of these can be a part of the emotional experience. Triggers of emotions are often seen as context-specific phenomena (Stemmler, Heldmann, Pauls, \& Scherer, 2001; Beard, Humberstone, \& Clayton, 2014). Among the most common triggers appear to be peer learners' experiences, views and culture (Ytreberg and Aars, 2015), the role of facilitation (Rogers and Freiberg, 1994), environmental settings and spaces (e.g. outdoors or indoors) (Kelz, Evans, \& Röderer, 2015), and methods, for example, simulation activities, problem-solving tasks, role plays and reflection (Chan, 2017). At times, more generic 
factors like weather and food can also trigger emotions and, thus, affect one's learning performance (Livornese and Vedder, 2017).

Despite emotional triggers being ubiquitous, some triggers assist learning in particular areas more than others. Nadler and Luckner (1992), for instance, illuminate the importance of newness in experiential learning courses. This can include new activities, environments and relationships, and frequently engenders feelings of fear, anxiety, exhaustion, camaraderie, frustration and joy. In experiential learning courses, such physical, mental, emotional, spiritual and environmental reactions are often magnified and experienced in clearer and more intense ways than they would at home or work. The more course participants digest, synthesise and assimilate what is happening to them, the more self-knowledge is available for change, conclude Nadler and Luckner.

These features appear to be noticeable in experiential learning courses like Outward Bound (OB). Some studies (Atchley, Strayer, \& Atchley, 2012; Hattie, Marsh, Neill, \& Richards, 1997) report that OB courses can obtain notable outcomes, have long lasting and life-changing effects on participants' development and self-actualisation. In the Australian context, James Neill, Gary Richards and Herbert Marsh have contributed extensively to the literature on OB. Their work has contributed to understanding the multiple dimensions of self-concept (Marsh, Richards, \& Barnes, 1986), notions of challenge and support (Neill and Dias, 2002), outcomes of outdoors education programs (Hattie, et al., 1997) and advance the importance of physical activity in nature (Mackay and Neill, 2010).

The discourse of triggers of emotional highs is based on ten recommendations on positive emotions in learning noted by Rantala and Määttä (2012). These recommendations on how to trigger emotional high experiences (they refer to them as 'joy in learning') include elements such 
as individual freedom, the possibility to learn from one's own starting point, and the importance of sharing and succeeding through difficulties. The study of Rantala \& Määttä was conducted in an elementary school classroom, however it can have consequences for the broader domain of understanding emotional highs and its triggers. Importantly, studying triggers of emotional highs with a group of adult learners in experiential learning environment could illuminate not only different perspectives, but also disclose particularities specific to this learning context.

\section{Research Focus}

[Figure 1 near here]

To illustrate the relationship between emotional highs and its triggers, an Iceberg metaphor (see Figure 1) is utilised. This is similar to Rauterberg's (2010) iceberg model, where the top part is considered as the conscious and the bottom part as the unconscious. The main difference is that Rauterberg refers to mind as the visible or conscious part of the iceberg, while in this study the entire iceberg is seen as emotional experience, from the state of emergence to the moment of awareness. The 'visible' tip of the iceberg here refers to the emotional experience that may be recognised by the learner (e.g. 'I feel fantastic'), and at times may also observed by external others, like facilitators. The 'invisible' bottom part of the iceberg refers to events, experiences, energies that have triggered the emotion. Looking at the bottom part, it is possible to reveal a wider and more holistic perspective on emotional experiences. By excluding any of these elements, emotion is not likely to emerge.

This embeds an ontological assumption that an emotional high experience is not just a short bodily reaction, and it may be insufficient to study a learner's lived experience of the 
phenomenon alone. It is equally crucial to study triggers of emotional highs (Corstorphine, 2006). This underpins the research question of this study: What are the triggers that lead to emotional highs in experiential learning?

The research question aims to understand the often invisible component of the emotional experience. By focusing on emotional triggers, it invites further and deeper level of interpretation. The 'triggers of emotional highs' here are viewed neither as a defined chain of activity, nor as a notion applicable to all learners and learning situations. Instead, the question focuses on the experiences of learners and how they make sense of what triggers their emotional highs.

This study acknowledges that triggers do not necessarily follow any laws or mechanisms that predict a certain behaviour or emotion (e.g. Frijda, 1988); nor are they scripts that have causal and temporal order (e.g. Widen and Russell, 2010). In fact, triggers are seen here, as Fenwick, Edwards \& Sawchuk (2011) put it, 'messy, slippery and indeterminate' (p. vii). The research question has two implications. On the one hand, this question requires an approach that allows participants to make sense of their experience by reflecting on it. On the other hand, triggers are seen as part of the whole emotional highs experience. This question does not necessarily aim to define a chain of concrete triggers that would guarantee a certain causeeffect result. Triggers here are viewed rather as stimuli upon and of the individual that happen in a sociocultural environment. Ultimately, the study assumes if the emotional high can be experienced similarly by different people, it may have some common ground of organised or disorganised elements leading to it.

The notion of emotional highs has been chosen for the following reasons. First, a discourse on emotional highs is specified as a practically applicable phenomenon, not an 
ambiguous term in educational scholarship. Following Briscoe's (2012) and Zeivots' (2016) initiatives, this study attempts to provide a sophisticated discourse on real learning experiences that meaningfully affect the learner. Second, educators, facilitators and scholars might find this study insightful as it not only attempts to unravel emotion as an experience, but also provides an account of learners that at times is missed or, often unconsciously, overpowered by facilitators' own world-views and interpretations.

Notably, this study does not extol positive emotions as the single answer to the challenges of experiential learning. Instead, it aims to take a more in-depth view of the emotional highs and, more importantly, assist in better understanding positive emotional experiences in the learning environment.

\section{Methodology}

A suitable method was sought to illustrate the triggers that lead to emotional highs. This was challenging because such triggers in experiential learning can be physical, palpable, socially constructed, or invisible.

Phenomenology was initially seen as a suitable approach as it focuses on the lived experience of learners and human perceptions of the world in which they live (Langdridge, 2007). The challenge is that it may not be sufficient to describe lived experience alone to understand what triggers emotional highs. To identify triggers a certain amount of sense making and reflection is required to clarify the conditions that lead to some level of understanding (Holroyd, 2007). This is where hermeneutics or interpretation and application of one's 
experience (Schmidt, 2016) can contribute to enquiry. Combining phenomenology and hermeneutics, so called hermeneutic phenomenology can be applied as a suitable methodology.

Hermeneutic phenomenology is used here as an overarching methodology. Although the lived experience remains an interest, the core of this study is concerned with hermeneutics - how people make sense of their experiences. Hermeneutics goes beyond a pure description of concepts and look for meanings embedded in common practices (Lopez and Willis, 2004). In this case, triggers of emotional highs are the points of interest.

To study the triggers of emotional highs, a deliberate decision was made to approach the phenomenon as an experience. This allows illumination of features and particularities of emotional highs, without utilising models that may be limiting. It is founded in the ontological view that lived experience is an interpretative process (Van Manen, 2016), which makes the hermeneutic phenomenology suitable to this study.

This study required the selection of specific learners and learning events that would allow the phenomenon and its triggers to be accessible. In the learning events the phenomenon should emerge multiple times and in multiple ways to provide enough suitable experiences to reflect upon. Experiential learning courses were selected because they typically address the learner's cognitive, physical, emotional and spiritual aspects in ways that may provide a wide spectrum of triggers of emotional experiences. These courses are known for dealing with emotional highs and lows (Andresen, Boud, \& Cohen, 2000).

\section{The Study}

This study focused on experiences of adult learners who participated in one of three 
experiential learning courses in Australia. OB conducted two of the courses and Collective Possibilities (CP) one of them. All courses were leadership-themed, involved experiential learning activities and aimed to foster personal growth, self-actualisation and social skills. The three courses were residential (OB1 - eight days, $\mathrm{OB} 2$ - seven days, $\mathrm{CP}$ - four days) and each had an equal number of days indoors and outdoors. The outdoors part involved learning activities in wilderness areas; in case of $\mathrm{OB}$ the participants moved through a national park both day and night.

The philosophy behind the three courses was that experience is an integral part of learning. The program of the courses was diverse and changed from day to day. The activities included hiking, abseiling, crossing rivers, sleeping outdoors in sleeping bags and problem solving tasks. While some activities were physical, others involved rather reflective practices. One of them was called Value path (OB) where participants spent around two hours walking alone through the field, passing interactive checkpoints and reflecting.

The total number of adult learners in the courses was comparatively low: 12 from OB1; eight from OB2; and 18 from $\mathrm{CP}$. This study focused on the experiences of 15 selected participants from the three courses; an average of five participants per course. The sample was diverse in gender, age and location; ages ranged from mid-twenties to early seventies, and there were similar numbers of women and men representing different Australian states.

This study followed a two-stage research design. The first stage involved a short participant questionnaire received at the end of the course. The questionnaire was designed as a brief experience checklist and was used to gather potential participants' contact details for the second stage, not as data. 
The second stage consisted of in-depth interviews with participants who agreed to continue with the study. The participants were asked to construct an emotional graph (Zeivots 2015) that focused on their emotional experiences throughout the course. When finished, most graphs resembled a heart rate diagram with several peaks and lows across the course. Learners were invited to speak about two to four emotional highs. This was followed by the sense-making part, where participants were encouraged to reflect on what may have triggered the highs. The following questions were used to prompt rich accounts.

- If you think about this (emotional high) experience, how could you replicate it somewhere in future?

- What made you feel good in this (emotional high) moment?

- What are the key ingredients of this experience?

\section{Data Analysis}

To study triggers of emotional highs, participants were asked to reflect on their lived experience within their courses and not to generalise to their everyday, or seemingly similar, experiences or knowledge. To examine this, the six-step approach (Smith, Larkin, \& Flowers, 2009) was used. In brief, the six-step approach is based on Interpretative Phenomenology Analysis (IPA) and involves engaging with data, initial data noting, developing emerging themes and mapping connections and patterns. This study focused exclusively on illuminating themes that emerged from participants' accounts. Such themes 'reflect a synergistic process of description and interpretation' (p. 92). 
One of the key IPA elements is the notion that participants are the ones who experience the phenomenon and therefore should be considered to have expertise in that phenomenon (Reid, Flowers, \& Larkin, 2005). Their narratives can offer an understanding of their emotions and thoughts. Researchers at times can assist in the sense-making process, as having an experience with the phenomenon does not necessarily mean one can consciously formulate and analyse it in words. Essentially, IPA does not aim to gather direct, unproblematic or true facts through the interviews. The focus here is rather on understanding the participants' perspectives and to seriously consider their meaning-full claims (Larkin, Watts, \& Clifton, 2006).

\section{Limitations}

One of the key challenges of hermeneutic phenomenology and this study is how to translate the insights of phenomenological philosophy into a coherent analysis of third person data (Smith, et al., 2009). According to Plager (1994), the meaning documented by the researcher will have invariably been interpreted and the interviewee's perception of reality may be deformed.

Learning contexts of the selected courses can be seen as limiting because they involved relatively similar methodologies, philosophies, facilitation styles and expected results. The outcomes presented in this study are likely to appear in programs promoted by training culture of the selected organisations. More diverse courses could have showcased a wider range of outcomes.

\section{Findings}


This study was concerned with understanding the triggers that lead to emotional highs. Triggers here are understood, but not limited to, individual, cultural and social aspects that, according to participants, have led to emotional high experiences. A wide spectrum of triggers was identified, with each participant mentioning between two and six triggers.

The process of making sense of triggers appeared to be complex and something one typically is not used to reflecting about. For many, the first reaction after being asked what triggered their emotional highs was surprise, silence or deep contemplation. 'That's a really hard question' (Susan OB2), and 'Not too sure. That's something I need to think about' (Kirsty CP) were among the common responses (participant pseudonyms are used here).

After taking a moment to reflect, participants however managed to point out some of the triggers of emotional highs. The more one engaged in reflection, the more triggers were indicated. The triggers did not appear to follow any logical system and ranged across various categories, including physical, mental, emotional, spiritual, environmental and cultural. The accounts of participants included triggers such as completing a task (Ryan OB1); making connections (Diane CP); achievement (Helen OB1); getting out of fear (Robert OB1); and a sense of relief (Thomas OB1).

Many triggers appear to be associated with social context. Being in a range of situations where participants engage with team building activities such as group reflections and values sharing appeared to be crucial for emotional highs to emerge. 'To get those feelings again it would be a social situation,' concluded Leanne (CP). Similarly, Richard (OB2) emphasised the importance of sharing and being with others as opposed to being alone: 'Unless I was sharing that [emotional high] moment, that moment would not have been even half as important.' 
At the core of the study is the focus on the triggers of emotional highs. The following eight themes emerged as characteristics of these triggers: Sense of being pushed; Exhaustion; Sense of safety and support; Escaping one's environment; Out-of-me experience; Sense of being in, and interacting with, nature; Invitation to explore; and Acceptance. These themes will now be discussed in detail.

Sense of being pushed. The presence of physical and emotional challenges were considered among the major triggers of emotional highs. OB abseiling experience, for instance, appeared to trigger emotional highs for many. While it was a pleasurable experience for some, for others it was a moment filled with multiple emotional and physical challenges. Robert (OB1), the oldest and the heaviest participant in his course, 'was so stressed out that morning because I did not want to get over that cliff'. He made it clear to the others that he was not going to abseil. Facilitators tried to encourage him and, as Robert recalled, 'push yourself how far you want to go. Then you can pull out if you want'. After taking a moment, Robert suited up and pushed himself as far as he could until he reached the point when he was ready to pull out. He was pulled back to the starting position. Later, seeing other participants abseiling, he started querying facilitators about the safety of abseiling. He asked how strong the rope was and learned that it could hold the weight of several cars. The response made him realise that 'if that is true, then I'm not gonna die. Get over yourself and just do it. I know they're not going to put our lives at risk anyway'. After several attempts to quit, Robert abseiled. Consequently, it turned out to be one of his key emotional highs in the entire course.

Challenges differed from person to person and yet they demonstrated several commonalities. First, learners seemed to operate differently when they were pushed externally. Experiences hidden in the challenging moments were considered as potential triggers to affect 
learners' values, attitudes and ideas, and frequently prompt emotional highs. Second, in retrospect the learner could see the worth and necessity of being pushed. Experiences of being challenged and pushed are not always a ticket to emotional highs. Although several participants referred to challenges as must-have experiences to achieve emotional highs, challenges were rather seen as prompts to open more avenues and opportunities for learning. If a challenge does not come across as worthwhile and beneficial, it may thwart learners from emotional high experiences. Third, the role of external triggers such as facilitators and sociomaterial objects appeared to be important in 'pushing' the learner. Similarly, the role of the learner was crucial to the process of reaching emotional highs. In most cases a learner's deep participation and engagement were required because they not only involve action, effort and drive but also give the learner time and space to personalise the 'pushed' learning experience.

Exhaustion. Being exhausted is not typically seen as a meaningful experience, nor is it something people desire. In the context of this study however many participants mentioned it as a trigger for emotional highs. Being exhausted appeared to not only assist the learning process, but also reveal vulnerabilities, which at times were useful for thinking clearly, becoming accepting and letting go. Susan (OB2) reflects, 'I was exhausted, I was emotional ... they send you on a two hour journey. You're so raw that it allows you to ... think deeply about what's important.' According to Sophie (CP), through exhaustion 'you give up yourself a bit, you become vulnerable, you allow yourself to be open'. Altogether, physical exhaustion was reported as often as mental and emotional exhaustion - at times all at the same time. Importantly, for exhaustion to be beneficial for learning, it appears important that there be a safe environment.

Sense of safety and support. Experiential learning courses are often perceived as challenging because they take participants out of, or away from, their comfort zones. Many 
stressed that exhaustion and being pushed experiences could trigger emotional highs, but only because the processes took place in safe and supportive environments. 'I wouldn't be able to walk into apartment and open up to someone like I did that day,' describes Thomas (OB1) referring to an evening reflection after an extensive walk. 'It was quite hard to share a few tears when you're a bloke. It was good to have that response from a crowd, get support there, and feel comfortable for sharing my personal side with a group that wouldn't judge you.' Three types of Sense of safety and support were observed: physical, emotional, and social.

Escaping one's environment. Many people have little time and often no reason to take time out and reflect on their lives. A notion of escaping one's environment implies temporarily being away from objects, artefacts and distractions that typically affect one's routine, examples being the family, work, routine, responsibilities, and, extensively, mobile phone. Many emotional layers, both wanted and unwanted, seem to be removed when away from these familiar and often comforting activities. Escaping one's environment differed from case to case and included getting away from one's adopted role in the family; low self-esteem (Caitlin OB1); day-to-day problems on your mind (Kirra OB1); and long drawn out quarrels (Diane CP). Ultimately, temporarily going away from one's environment and routines can be beneficial and worthwhile, especially for one's learning process.

Out-of-me experience. Another trigger of emotional highs was an experience where a learner felt they were stepping out of their habitual life. Often these experiences emerged as surprising; quasi-paranormal bodily revelations; and something one could not imagine as possible. Richard (OB2) recalls his out-of-me experience from the course that assisted him to notice how other people are mistreated by his leadership. 'Everyone was trying to be a leader, including me,' Richard describes, 'I was taking over, which is a natural thing I do. I did what I normally do, which 
is push them [other participants] away. And then... I could see THAT. It was the first time I actually saw THAT.' The experience seemed as though it was not consciously guided by the learner self. In other words, a common association with an out-of-me experience was a sense of someone else being in the body. During these experiences the learner appeared to go beyond the known, enter the not-yet-existent, and thus take on new learning experiences.

Sense of being in, and interacting with, nature. There is something about learning in nature, the wilderness, and the outdoors that appeared favourable for highs to emerge. Iterative references to nature can be observed across participants' accounts of living and non-living features such as 'being with wombats, kangaroos, where the river is' (Robert OB1). Similarly, nature often came across through certain activities, such as hiking, setting up a tent, building a fire, and sleeping under the open sky. Kirra (OB1) describes her mood when drawing contrasts between indoor and outdoor learning environments. 'Being outdoors is wonderful! I like to light a fire, go bushwalking. Then we came in for the next four days. I don't like it as much'. When asked to consider how to replicate emotional high experiences, Caitlin (OB1) states 'I have to go outside.' For Ryan (OB1) learning in nature has 'that genuine excitement'. Paradoxically however, participants found it difficult to further specify what 'nature' exactly does in this process. A few participants implied that learning in nature was calming, exciting, and practical, as well as providing more possibilities for divergent learning encounters and making it easier to engage with learning.

Invitation to explore. This theme was often revealed through open-ended reflective questions that took the learner on a journey of discovery. Mostly these questions were so called 'why' questions like 'Why did you do that?' and 'Why is this important?' Answering such questions, especially when one has meaningful experiences to reflect on, may have been seen by 
some as daunting and by others as beneficial. These questions often did not seek the obvious; rather they provoked, invited exploration, and illuminated the depth of more profound understanding. Meaningful reflections seemed to allow learning 'to be absorbed' (Martin OB1) as opposed to providing clear cut-off answers. 'The reason why it's not so simple is because we're dealing with values, emotions', recognises Martin (OB2). He concludes that 'these things are from your childhood to present, it has a major impact on the way you think, see the world and view yourself.' The main emotional high for Diane (CP), as she explains, was 'developing an understanding of why it's frustrating, why it's challenging or even understanding how I may combat that.' The exploration process may exercise the rational dimensions of the learner as much as emotional, physical, and spiritual dimensions that at times lead to emotional highs.

Acceptance. The process of responding to 'why' types of questions may reveal meaningful discoveries and observations, but these are not always sufficient for emotional highs to emerge. Acceptance is seen as crucial for highs to emerge. 'I probably became more accepting of myself and found that there's not a perfect person,' reflects shy Caitlin (OB1) who has struggled to accept herself for a long time. 'You can be who you are and still have a role to play. Recognise that your strengths are someone else's weaknesses.' Martin (OB1) however notices that other people values are not wrong, they are different. 'It's how you see the world. You see, it opened up my mind about accepting other people.' Although often perceived as less visible or important, acceptance seemed to trigger meaningful experiences, like openness, relief, comfort, and encouragement. It was a common assumption among participants that acceptance is possibly the hardest trigger to achieve. Three categories of acceptance were identified: accepting oneself; accepting the world; and getting accepted by the world. 


\section{Discussion}

There is something about experiential learning environments, especially those occurring in nature, that assist emotional highs to emerge and become obvious. On the assumption that this 'something' is beyond our awareness, this study drew on the Iceberg metaphor to study emotional experiences. In short, the Iceberg metaphor acknowledges there are emotional experiences that learners can be more aware of and embrace (the visible top of the iceberg) and there are unexposed triggers that assist in creation of the experience (the invisible bottom of the iceberg). Both aspects are crucial for understanding emotional experiences.

The findings section outlined a number of themes that were associated with the triggers of emotional highs. Among the core triggers was the notion of being pushed. The Sense of being pushed is a metaphor to illustrate the presence of external stimulants in the learning environment, often facilitators, participants or natural settings. Being pushed may appear similar to being challenged. The main difference between these notions is that a challenge can come from the learner's self. The Sense of being pushed, on the other hand, embraces aspects of being unexpectedly out of one's comfort zone, with no sense of how to proceed or how long it will take. This can affect the level of difficulty and the structure of the experience, particularly at the beginning. This study reveals that learners seem to operate differently when they have a Sense of being pushed.

There is extensive literature on learning through challenges which has ties with the phenomenon examined, however few of them explicitly refer to 'external push'. Snell (1992) uses the notion of 'perturbation' to heighten opportunity for more meaningful learning. Perturbation, Snell argues, is disturbance rather than distress. In other words, it is a deviation 
from everyday life that at times is important for a society that puts emphasis on structure, routine, and control.

A number of studies in outdoors education have shown that the combination of challenge, mastery, and succeeding can lead to participant growth (Hopkins and Putnam, 2013; McKenzie, 2000). Despite the importance of success, perceived challenges and risk play a role in achieving positive outcomes and emotions (Beard and Wilson, 2013). The notion of 'Edgework' is a similar metaphor to describe the limit of the personal known; it is the experiential barrier from which we either turn back or break through. The more people get closer to the edge, the more there is an increased sense of unknown (Nadler and Luckner, 1992).

Individual perception of risk and challenge, some scholars warn, is different and it cannot be seen in isolation of learner's unique background (Boniface, 2000; Leberman and Martin, 2002). Being pushed in the learning environment therefore cannot be seen as a direct cause of emotional highs. Rather, an external push opens unique, creative and divergent pathways for learning, which possibly would not occur if a challenge had been designed by the learner only. Dimensions of ambiguity, surprise and the unknown seem to be present when one is being pushed. In the beginning, the experience of being pushed tends to be unexpected and emergent, but what happens afterwards can determine the possibility of the learner reaching emotional highs. For an emotional high to emerge, the learner should be able to see retrospectively the value of being pushed.

Another key theme observed was Escaping one's environment. It happens, often unconsciously, that our routines and habits can blind us to other and possibly better possibilities. The trigger suggests that being away or temporally escaping one's environment can be not only pleasant, but beneficial for learning. Some participants call it the phenomenon of 'getting out of 
your experience to see it better' (Giuseppe CP). This is similar to Einstein's idea that 'a person starts to live when he can live outside himself. Few are those who see with their own eyes and feel with their own hearts' (Perry, 2004, p. v). In other words, by being temporarily away from one's life, people can connect better with themselves through awareness and action.

Literature shows that a temporal escape can be beneficial as at times it allows one to become someone else (Molesworth, 2009). Whilst it is believed that one is always becoming

(Clegg, Kornberger, \& Rhodes, 2005), becoming someone else, according to Clarke and Hennig (2013), is described as a useful mean to transform themselves. This can affect learners extensively. Among the main changes is that learners do not have to be themselves anymore.

Some studies focus on escaping the everyday environment through learning in nature. Morgan (2010) uses the notion of travel that can provide an encounter with otherness. The scholar analyses various types of journeys and venues that can assist the learner to broaden the mind and elicit development. Nature and wilderness, he states, have significant potential of it. Similarly, another study (Atchley, et al., 2012) has found that a four day immersion in nature, and disconnecting from multi-media and technology can increase performance in problemsolving and creativity by $50 \%$.

\section{Conclusions}

This study has explored the triggers that lead to emotional highs in experiential learning. Hermeneutic phenomenology was used as an overarching lens to understand how people make sense of their emotional experiences. At the ontological level, emotions in this study were approached as individual experiences. The main benefit of this approach was to perceive 
emotions as unique to each individual rather than pre-defined phenomena. Altogether eight themes were discussed: Sense of being pushed; Exhaustion; Sense of safety and support; Escaping one's environment; Out-of-me experience; Sense of being in, and interacting with, nature; Invitation to explore; and Acceptance.

The findings of this study suggest that the triggers are integral to the experience of emotional highs. When designing learning courses, practitioners should be aware of learner's lived experiences and sensitivities, and what might trigger their emotional highs. Understanding triggers of emotional highs may be beneficial for educators who seek to recognise and find ways to harness and facilitate meaningful emotional experiences in the learning environment.

This study suggests that more understanding is needed on how these triggers interact. Rather than approaching triggers as individual elements that act independently, a robust understanding of the relationships they form would be particularly useful. An intriguing connection, for instance, was found between two emotional high triggers: Escaping one's environment and Sense of being in, and interacting with, nature. Further research on learning in nature as a temporal escape from one's usual environment seems warranted: What implications does this have for learners and how it affects learning? Would other spaces work just as well? Similar temporal escape metaphors during learning should also be further discussed, especially as they appear to have common foundations with escaping one's everyday environment. 


\section{References}

Ainley, M., Corrigan, M., \& Richardson, N. (2005). Students, tasks and emotions: Identifying the contribution of emotions to students' reading of popular culture and popular science texts. Learning and Instruction, 15(5), pp. 433-447.

Andresen, L., Boud, D., \& Cohen, R. (2000). Experience-based learning. In G. Foley (Ed.), Understanding adult education and training (2nd ed., pp. 225-239). Sydney: Allen \& Unwin.

Atchley, R., Strayer, D., \& Atchley, P. (2012). Creativity in the wild: Improving creative reasoning through immersion in natural settings. PloS One, 7(12), pp. 1-3.

Beard, C., Humberstone, B., \& Clayton, B. (2014). Positive emotions: passionate scholarship and student transformation. Teaching in Higher Education, 19(6), pp. 630-643.

Beard, C., \& Wilson, J. (2013). Experiential learning: A handbook for education, training and coaching. London: Kogan Page Publishers.

Boniface, M. (2000). Towards an understanding of flow and other positive experience phenomena within outdoor and adventurous activities. Journal of Adventure Education \& Outdoor Learning, 1(1), pp. 55-68.

Boud, D., Cohen, R., \& Walker, D. (1993). Using experience for learning. Milton Keynes: Society for Research into Higher Education and Open University Press.

Boud, D., \& Miller, N. (1996). Working with experience: Animating learning. London: Routledge.

Briscoe, F. (2012). Anarchist, neoliberal, \& democratic decision-making: Deepening the joy in learning and teaching. Educational Studies, 48(1), pp. 76-102.

Chan, Z. (2017). Poetry writing and artistic ability in problem-based learning. International Journal on Disability and Human Development, 16(1), pp. 37-44. 
Clarke, M., \& Hennig, B. (2013). Motivation as ethical self-formation. Educational Philosophy and Theory, 45(1), pp. 77-90.

Clegg, S., Kornberger, M., \& Rhodes, C. (2005). Learning/becoming/organizing. Organization, 12(2), pp. 147-167.

Corstorphine, E. (2006). Cognitive-emotional-behavioural therapy for the eating disorders: Working with beliefs about emotions. European Eating Disorders Review, 14(6), pp. 448-461.

Dewey, J. (1938/1975). Education and experience. New York: Macmillan.

Dirkx, J. (2008). The meaning and role of emotions in adult learning. New Directions for Adult and Continuing Education, 2008(120), pp. 7-18.

Fenwick, T., Edwards, R., \& Sawchuk, P. (2011). Emerging approaches to educational research: Tracing the socio-material. London: Routledge.

Fredrickson, B. (2004). The broaden-and-build theory of positive emotions. Philosophical Transactions of the Royal Society B: Biological Sciences, 359(1449), pp. 1367-1378.

Frijda, N. (1988). The laws of emotion. American Psychologist, 43(5), pp. 349-358.

Gläser-Zikuda, M., Fuß, S., Laukenmann, M., Metz, K., \& Randler, C. (2005). Promoting students' emotions and achievement: Instructional design and evaluation of the ECOLE-approach. Learning and Instruction, 15(5), pp. 481-495.

Harris, J. (1996). Animating learning in teams: A Gestalt approach. In D. Boud \& N. Miller (Eds.), Working with experience: Animating learning (pp. 157-170). London: Routledge.

Hattie, J., Marsh, H., Neill, J., \& Richards, G. (1997). Adventure education and Outward Bound: Out-ofclass experiences that make a lasting difference. Review of Educational Research, 67(1), pp. 4387.

Hayllar, B. (2000). Outdoor management development: A phenomenological analysis. Sydney: University of Technology, Sydney.

Heron, J. (1996). Helping whole people learn. In D. Boud \& N. Miller (Eds.), Working with experience: Animating learning (pp. 75-94). London: Routledge. 
Hochschild, A. (1983/2003). The managed heart: Commercialization of human feeling. Berkeley: University of California Press.

Holroyd, A. (2007). Interpretive hermeneutic phenomenology: Clarifying understanding. Indo-Pacific Journal of Phenomenology, 7(2), pp. 1-12.

Hopkins, D., \& Putnam, R. (2013). Personal growth through adventure. New York: Routledge.

Järvenoja, H., \& Järvelä, S. (2005). How students describe the sources of their emotional and motivational experiences during the learning process: A qualitative approach. Learning and Instruction, 15(5), pp. 465-480.

Kelz, C., Evans, G., \& Röderer, K. (2015). The restorative effects of redesigning the schoolyard: A multimethodological, quasi-experimental study in rural Austrian middle schools. Environment and Behavior, 47(2), pp. 119-139.

Krapp, A. (2005). Basic needs and the development of interest and intrinsic motivational orientations. Learning and Instruction, 15(5), pp. 381-395.

Langdridge, D. (2007). Phenomenological psychology: Theory, research and method. Harlow, Essex: Pearson.

Larkin, M., Watts, S., \& Clifton, E. (2006). Giving voice and making sense in interpretative phenomenological analysis. Qualitative Research in Psychology, 3(2), pp. 102-120.

Leberman, S., \& Martin, A. (2002). Does pushing comfort zones produce peak learning experiences? Australian Journal of Outdoor Education, 7(1), pp. 71-81.

Livornese, K., \& Vedder, J. (2017). The emotional well-being of nurses and nurse leaders in crisis. Nursing Administration Quarterly, 41(2), pp. 144-150.

Lopez, K., \& Willis, D. (2004). Descriptive versus interpretive phenomenology: Their contributions to nursing knowledge. Qualitative Health Research, 14(5), pp. 726-735.

Mackay, G., \& Neill, J. (2010). The effect of 'green exercise' on state anxiety and the role of exercise duration, intensity, and greenness: A quasi-experimental study. Psychology of Sport and Exercise, 11(3), pp. 238-245. 
Marsh, H., Richards, G., \& Barnes, J. (1986). Multidimensional self-concepts: The effect of participation in an Outward Bound Program. Journal of Personality and Social Psychology, 50(1), p 195.

McKenzie, M. (2000). How are adventure education program outcomes achieved?: A review of the literature. Australian Journal of Outdoor Education, 5(1), pp. 19-28.

Molesworth, M. (2009). Adults' consumption of videogames as imaginative escape from routine. NA Advances in Consumer Research, vol. 36, pp. 378-383

Morgan, A. (2010). Journeys into transformation travel to an 'other' place as a vehicle for transformative learning. Journal of Transformative Education, 8(4), pp. 246-268.

Nadler, R., \& Luckner, J. (1992). Processing the adventure experience. Dubuque: Kendall/Hunt.

Neill, J., \& Dias, K. (2002). Challenge and support in Outward Bound: The double-edged sword. Outward Bound International Newsletter, 10(1), pp. 1-7.

Perry, Y. (2004). More than meets the eye. Nashville, TN: Yvonne Perry.

Picard, R. W., Papert, S., Bender, W., Blumberg, B., Breazeal, C., Cavallo, D., . . Strohecker, C. (2004). Affective learning - A manifesto. BT Technology Journal, 22(4), pp. 253-269.

Plager, K. (1994). Hermeneutic phenomenology: A methodology for family health and health promotion study in nursing. In P. Benner (Ed.), Interpretive phenomenology: Embodiment, caring, and ethics in health and illness (pp. 65-83). Thousand Oaks, CA: Sage.

Plutchik, R. (1980). Emotion: A psychoevolutionary synthesis. New York: Harper \& Row.

Rantala, T., \& Määttä, K. (2012). Ten theses of the joy of learning at primary schools. Early Child Development \& Care, 182(1), pp. 87-105.

Rauterberg, M. (2010). Emotions: The voice of the unconscious. ICEC'10 proceedings of the 9th international conference on entertainment computing, pp. 205-215.

Reid, K., Flowers, P., \& Larkin, M. (2005). Exploring lived experience. Psychologist, 18(1), pp. 20-23.

Rodríguez-Ardura, I., \& Meseguer-Artola, A. (2017). Flow in e-learning: What drives it and why it matters. British Journal of Educational Technology, 48(4), pp. 899-915.

Rogers, C. R., \& Freiberg, H. J. (1994). Freedom to learn. Columbus, OH: Merrill. 
Schmidt, L. (2016). Understanding hermeneutics. London: Routledge.

Schoel, J., Prouty, D., \& Radcliffe, P. (1988). Islands of healing: A guide to adventure based counseling Hamilton, MA: Project Adventure, Inc.

Shareski, D. (2017). Embracing a culture of joy. Bloomington: Solution Tree Press.

Smith, J., Larkin, M., \& Flowers, P. (2009). Interpretative phenomenological analysis: Theory, method and research. London: Sage.

Snell, R. (1992). Experiential learning at work: why can't it be painless? Personnel Review, 21(4), pp. 1226.

Stemmler, G., Heldmann, M., Pauls, C., \& Scherer, T. (2001). Constraints for emotion specificity in fear and anger: The context counts. Psychophysiology, 38(2), pp. 275-291.

Takahashi, S., \& Saito, E. (2013). Unraveling the process and meaning of problem-based learning experiences. Higher Education, 66(6), pp. 693-706.

Vacharkulksemsuk, T., \& Fredrickson, B. (2013). Looking back and glimpsing forward: The Broadenand-Build Theory of Positive Emotions as applied to organizations. In A. Bakker (Ed.), Advances in positive organizational psychology, vol. 1 (pp. 45-60). Bingley, UK: Emerald Group Publishing.

Van Manen, M. (2016). Phenomenology of practice: Meaning-giving methods in phenomenological research and writing. New York: Routledge.

Waugh, C., \& Fredrickson, B. (2006). Nice to know you: Positive emotions, self-other overlap and complex understanding in the formation of a new relationship. The Journal of Positive Psychology, 1(2), pp. 93-106.

Widen, S., \& Russell, J. (2010). Children's scripts for social emotions: Causes and consequences are more central than are facial expressions. British Journal of Developmental Psychology, 28(3), pp. 565581.

Wolfe, P. (2006). The role of meaning and emotion in learning. New Directions for Adult and Continuing Education, 2006(110), pp. 35-41. 
Ytreberg, B., \& Aars, M. (2015). Emotions in true peer teaching and learning: Physiotherapy students' experiences. European Journal of Physiotherapy, 17(1), pp. 9-18.

Zeivots, S. (2015). Lived experience of emotional highs in experiential learning (Doctoral dissertation). University of Technology Sydney, Sydney.

Zeivots, S. (2016). Emotional highs in adult experiential learning. Australian Journal of Adult Learning, 56(3), pp. 353-373. 